\title{
Satisfaction with social care: the experiences of people from Chinese backgrounds with physical disabilities
}

\author{
Echo Yuet Wah Yeung $\mathrm{PhD}^{1}$, Martin Partridge $\mathrm{PhD}^{2}$ and Fiona Irvine $\mathrm{PhD}^{3}$ \\ ${ }^{1}$ Faculty of Education, Community and Health, Liverpool John Moores University, Liverpool, UK, ${ }^{2}$ Faculty of Health \\ Sciences, Staffordshire University, Staffordshire, UK and ${ }^{3}$ School of Health and Population Science, The University of \\ Birmingham, Birmingham, UK
}

Accepted for publication 7 May 2015

\section{Correspondence \\ Echo Yuet Wah Yeung \\ Faculty of Education, \\ Community and Health \\ Liverpool John Moores University \\ Liverpool L3 2AJ, UK \\ E-mail: y.yeung@ljmu.ac.uk}

\section{What is known about this topic}

- Underutilisation of disability support services is common among people from Chinese backgrounds in England.

- A lack of knowledge of services available and language difference are known factors that lead to underutilisation.

- In traditional Chinese societies, family bears the main responsibility for looking after relatives with health and social care need.

\section{What this paper adds}

- Language difference creates a barrier to negotiating access to and navigating through social care.

- The cultural expectation of looking after their own and limited support from their small support network create tension during help-seeking.

- The perception that their voices will not be listened to discourages expression of opinions when services are not meeting their needs.

\begin{abstract}
The satisfaction of social care among service users provides an important indication of how services are performing. Although there is evidence to suggest that people from black and minority ethnic communities experience less satisfaction with social care than majority groups, there is little literature which focuses specifically on people from Chinese backgrounds in England. This article provides an opportunity to hear the voices of people from Chinese backgrounds and their experiences of social care for a physical disability. Individual semi-structured interviews and focus groups were conducted in 2012 and 2013 respectively with people from Chinese backgrounds who lived in England, were aged between 18 and 70, and received social care for a physical disability. Interview and focus group transcripts were analysed using a thematic approach. The findings show that language difference created a structural barrier for most participants to negotiating access to and navigating through social care. Language difference and the cultural expectation that families should look after their own were main factors that explained their late utilisation of social care. Because of limited social support, many families struggled to meet the long-term care needs of their relative with a physical disability and hence initially welcome the input of social care. However, many found that social care could not adequately meet their needs but did not feel that they had the right to voice their dissatisfaction. They would either stop using social care services or become more reliant on their family for support. Chinese welfare organisations play a crucial role to meet the cultural and linguistic needs of people from Chinese backgrounds. Closer collaboration between local authorities and Chinese welfare organisations is needed to enable an effective use of social care and community resources to meet the needs of people from Chinese backgrounds with physical disabilities.
\end{abstract}

Keywords: Chinese, physical disability, satisfaction level, social care

\section{Introduction}

The Chinese population of the UK has experienced a rapid growth in the past decade: it increased from
247,403 in 2001 to 393,141 in 2011 , making up $0.7 \%$ of the total population (Office for National Statistics 2012). Despite the growing Chinese population, statistics from the Health and Social Care Information 
Centre (2013) reveal that only $0.1 \%$ (205 out of 156,555) of adults with physical disability in England, received services provided or commissioned by local authority adult social care between April 2012 and March 2013, were from Chinese backgrounds. The underrepresentation of Chinese people in social care raises the question about fair access and treatment, which contradicts what the Equality Act (2010) and Equality Objectives Action Plan (DH 2012) set out to achieve. Studying the experiences of social care of people from Chinese backgrounds helps to address equality and diversity issues.

Studies examining experiences of social care of adults with physical illness find that poor staff attitudes, inefficiency and poor management of care are perceived to have negative implications for satisfaction levels (Manthorpe et al. 2008). Other studies to explore experiences of adult social care among different minority ethnic groups highlight some common themes. These include low levels of contact with formal services (Bignall \& Butt 2000, Liu et al. 2014), experiences of prejudicial assumptions, especially in relation to the role of informal carers (Chahal 2004, Katbamna et al. 2004, Chow et al. 2010) and a lack of information and awareness of the range of services available (Chahal 2004).

It is found that underutilisation of disability support service is commonplace among different minority ethnic communities (Bignall \& Butt 2000, Chahal 2004) and Chinese groups (Care Quality Commission 2010) in England. Broadly speaking, structural and cultural factors are used to explain low service use among people from Chinese backgrounds. A lack of knowledge of services available (Hiew et al. 2008, Liu et al. 2012) and language difference ( $\mathrm{Ng}$ et al. 2007, Waller et al. 2009) create difficulties for Chinese people to access services. There is ample evidence to support that limited language skills in English presents a challenge for Chinese people, especially among the first-generation immigrants, to access mainstream facilities (Wong 2006, Aspinall 2007, Liu et al. 2015). Although the use of interpreters can help to overcome communication barriers, it is often difficult to locate quality interpreting services (Rochelle \& Marks 2010, Koo 2012). A self-report survey reveals that among different minority ethnic groups, Chinese people experience more difficulty to communicate effectively with healthcare professionals and feel that their wishes are not respected in the healthcare decisionmaking process (Healthcare Commission 2008). Additionally, previous experience of discriminatory practice with mainstream provisions also deters Chinese people from initiating contact and engaging with public services (Huang \& Spurgeon 2006). We need to examine how these structural factors impact on the experiences of social care.

Conversely, cultural factors offer another perspective to understand why Chinese people are reluctant to seek help outside the confines of family. Cross-cultural studies report that Chinese people are less accepting of people with disabilities than people of European descent (Westbrook et al. 1993, Ryder et al. 2000). Because of the stigma associated with disabilities and the worry that the association with family members who experience disabilities will be exposed during the help-seeking process, many Chinese families are resistant to contact and engage with disability support services (Holroyd 2003, Yeung 2013). Moreover, self-management is a preferred strategy to manage health-related problems in Chinese societies (Kim et al. 2006, Liu et al. 2015); families are expected to take up the caring role for their family members (Chan 1987, Yu 2000). Involving 'outsiders' implies that the family is failing to fulfil their caring responsibility and will bring further shame to the family (Chan \& O'Connor 2008). As a result, seeking help outside the domestic sphere is often the last resort.

The above studies primarily focus on the experiences of use of health and social care services among older people ( $\mathrm{Yu}$ 2000, Liu et al. 2015) and people with mental health issues from the Chinese communities in England (Hiew et al. 2008, Koo 2012, Yeung et al. 2013). To date, the experience of social care of people from Chinese backgrounds with physical disabilities in England remains an unexplored territory. This paper aims to examine the factors affecting their experiences of social care. It also seeks to determine their levels of satisfaction with social care so that areas for service improvement could be identified.

\section{Research design}

This study adopted a qualitative methodology to explore the experiences of social care of Chinese people with physical disabilities (Moustakas 1994). We used the research approach advocated by Van Manen (1997) which gives scope to focus on the essential themes of experiencing social care for physical disabilities. The early stages of the study took a descriptive approach, using face-to-face semi-structured interviews to capture the experiences of participants; the later stages followed an interpretive approach, using focus groups to facilitate interpretation. Ethics approval was obtained from the National Social Care Research Ethics Committee and informed consent was sought before data collection commenced. Pseudonyms were used in this paper to protect participants' identity. 


\section{Recruitment and sampling}

We used purposive sampling to recruit people from a Chinese background, were aged between 18 and 70, had a physical impairment and were in receipt of social care services within 6 months before the time of the interview. Based on previous research experiences, we anticipated difficulties in recruiting participants from Chinese backgrounds with social care needs (Partridge 2013, Yeung et al. 2013). The dispersed Chinese population in the UK also makes recruitment more difficult (Dobbs et al. 2006). Thus, recruitment materials were sent to all local authority adult social care teams, and widely distributed to Chinese community centres and Chinese supermarkets in major cities. The recruitment leaflets and posters were produced in both Chinese (traditional and simplified version) and English so that potential participants with different language skills could consider taking part in the study. The majority of participants were recruited through Chinese community centres in cities such as Birmingham, London, Manchester and Newcastle. A small number of participants contacted the research team directly and expressed interest to take part in the study.

\section{Data collection}

We began the study by conducting individual semi-structured interviews with people from Chinese backgrounds who received social care services for a physical disability. We then took the findings from the interviews to the focus groups to validate and clarify our interpretation of participants' experiences. Two bilingual researchers and one English-speaking researcher conducted individual interviews. An interview schedule with a set of open-ended questions was used to guide the interview. We began the interviews with questions such as: 'what is your experience of social care?' and 'how did you first come into contact with social care?' These open-ended questions provided room for participants to freely articulate their experiences. The interviews lasted between 30 and 80 minutes and took place either in Chinese community centres or participants' homes. In total, 26 Chinese people (15 women and 11 men) with physical impairment were interviewed. We stopped recruiting participants once data saturation had been reached. Interviews were carried out in the preferred language of participants; 18 interviews were conducted in a Chinese dialect including 16 in Cantonese and 2 in Mandarin, and 8 interviews in English. In some interviews, family members were also present and contributed to the discussion.
In the second stage of the study, we invited all interviewees to take part in focus group discussions. Focus groups were used to open up new perspectives and give deeper understandings on themes which emerged from the interviews (Bradbury-Jones et al. 2009). Fourteen participants agreed to attend the focus groups; two focus groups were conducted in Cantonese (CSFG1 and CSFG2) and one in English (ESFG). All focus groups took place in Chinese community centres and lasted between 50 and 90 minutes. In the focus groups, we asked participants to discuss our findings, which helped to verify our interpretation and generate new understanding of their experiences. Contextual information that could not be recorded in the interviews and focus groups was captured in our field notes.

We did not encounter any major ethical dilemmas throughout the research process. However, a number of participants appeared to be emotionally upset when they talked about their experiences of living with a physical disability, and the demand placed on their families to look after them. When participants showed signs of distress, we offered them the option to take a break, have the interview re-scheduled or withdraw from the study. All participants chose to continue the interview as they felt that it was important to have their experiences shared and voices heard. Participants were given information about bilingual counselling services should they wish to seek support from them.

\section{Data analysis}

All the interviews and focus group conversations were audio recorded and fully transcribed. As meaning can be lost and misinterpreted in translation (Yeung 2013), analysis of data was undertaken in the language used during the process of data collection. All interview transcripts were read independently by three researchers of the research team; the two bilingual researchers examined all transcripts and the other researcher examined the English transcripts. Initial labelling of codes and themes was completed bilingually by using the words that participants used in the interviews. This helped to retain the original meaning of the raw data, which is vital in any qualitative study (Moustakas 1994). Verbatim quotations presented in this paper were translated into English.

The bilingual researchers worked out an English version of the Chinese codes and themes. The research team then discussed the initial analysis and came to an agreement of the final thematic representation. We went back to the original data repeatedly to make sure that key themes truly represented 
participants' experiences. Identified themes were presented to focus groups for validation. The same process was repeated for the analysis of focus group data. We compared the interview findings to the focus group data, explored for new meanings and insights and in the light of the new data, adjustments were made to the original analysis. We used the computer software QSR NVivo version 9 to manage the qualitative data. The software provides a transparent audit trail which enhances the credibility and trustworthiness of the study.

\section{Findings}

Table 1 shows participants' characteristics. Their age ranged from 19 to 69; most of them were over 50 years of age. The majority of the participants were immigrants, and originated from Hong Kong, Mainland China, Malaysia and Singapore. Most of them had physical impairments as a result of stroke or other long-term illnesses such as multiple sclerosis and Parkinson's disease. At the time of the interview, 23 participants lived in the community and three lived in care homes. Each participant was given a pseudonym and the pseudonyms used were based on how participants were introduced to the researcher. For example, if the participant was introduced by his or her Chinese name and with a formal title, a Chinese pseudonym with a formal title was assigned to the participant.

Emerging themes that help to understand participants' experiences of social care include 'experience of getting access to social care', 'language difference as a barrier to negotiating services' and 'attitudes of social care workers'. Two themes - 'reliance on personal resources' and 'using culturally specific services' - are preferred strategies used by participants to meet their social care needs.

\section{Experience of getting access to social care}

Participants spoke of the experiences of living with physical disabilities before they received support from social care. They described struggling to manage daily challenges and perform their social roles:

I really struggle; I want to go out by myself, prepare my own dinner. It's really difficult when there is no one to help. (Alan)

My husband passed away a few years ago. I am a single parent. I have to look after my 7-year-old daughter as well. I cannot do shopping without my daughter. She helps me to take the shopping from the shelves and put them in the car. (Hannah)
Despite these struggles, participants had to manage their care with limited support from their personal networks for a prolonged period before they received assistance from social care. They explained:

I didn't know what service was available, I just knew that I could try but I didn't know what exactly I should be asking for. (Mr Lau)

I didn't get in touch with anyone because I didn't know where to go or how to get help ... I didn't know what I was entitled to. (Angela)

Not knowing where and how to access social care was one of the reasons for not getting support early. The collective responses from focus group members affirmed that they had to wait for a crisis before support was offered from social care. In many cases, participants only came into contact with social care when their health deteriorated to the extent that required hospital treatment:

The only way you could get help was to be hospitalised and then you would have the service. You need to get into the system! (ESFG)

You know, the system works like this. Your condition has to become very serious to warrant their intervention. However, only the sufferers know the seriousness of the situation, we live with it every day ... you know, they (social workers) actually don't understand. (CSFG 1)

Feeling uncertain about their entitlement to services and being unfamiliar with the procedures involved impede help-seeking. This explains why many participants had to navigate through the healthcare system before they reached social care, which could have caused them delays in getting support and further confusions to their understanding of the organisation of social care.

\section{Language difference as a barrier to negotiating services}

Participants' pathway to social care was further compounded by language difference. Many participants encountered structural barriers to accessing social care because literature about services was not presented in their native language:

I don't know how to access services because I don't know English, I don't know how to ask for the information I need. (CSFG2)

Unable to comprehend disability literature can cause delays in contacting social care. This partly explains why most participants only reached social care at a crisis point. They also felt disoriented and were unable to be fully involved during the assess- 
Table 1 Participants' characteristics

\begin{tabular}{|c|c|c|c|c|c|c|c|}
\hline $\begin{array}{l}\text { Name } \\
\text { (pseudonym) }\end{array}$ & $\begin{array}{l}\text { Age/ } \\
\text { gender }\end{array}$ & Physical impairment & $\begin{array}{l}\text { Nature of social } \\
\text { care received }\end{array}$ & $\begin{array}{l}\text { Language } \\
\text { used in } \\
\text { interview }\end{array}$ & $\begin{array}{l}\text { Other } \\
\text { language/dialect } \\
\text { spoken }\end{array}$ & Living condition & Place of birth \\
\hline Mrs Wong & $69 / F$ & Movement impairment & Domiciliary care & Cantonese & Hakka & Lived alone & Hong Kong \\
\hline Mr Tse & $68 / \mathrm{M}$ & $\begin{array}{l}\text { Movement impairment } \\
\text { (wheelchair user) }\end{array}$ & $\begin{array}{l}\text { Day centre and } \\
\text { domiciliary care }\end{array}$ & Cantonese & - & With wife & Hong Kong \\
\hline Mr Lau & $50 / \mathrm{M}$ & Visual impairment & Day centre & Cantonese & - & With wife & Hong Kong \\
\hline Mrs Lin & $60 / \mathrm{F}$ & Movement impairment & Domiciliary care & Cantonese & - & With husband & Hong Kong \\
\hline Mr Chan & $64 / \mathrm{M}$ & Movement impairment & Day centre & Cantonese & - & With wife & Hong Kong \\
\hline Mr Fok & $62 / M$ & Movement impairment & Day centre & Cantonese & - & Lived alone & Hong Kong \\
\hline Mrs Lam & $64 / F$ & Movement impairment & Domiciliary care & Cantonese & - & Lived alone & Hong Kong \\
\hline Linda & $56 / \mathrm{F}$ & Movement impairment & Domiciliary care & Cantonese & English & Lived alone & Hong Kong \\
\hline Mrs Lee & $60 / F$ & Movement impairment & Domiciliary care & Cantonese & English & Lived alone & Hong Kong \\
\hline Mrs Smith & $61 / F$ & Movement impairment & Day centre & Cantonese & English & Lived alone & Hong Kong \\
\hline Mrs Ho & $64 / F$ & $\begin{array}{l}\text { Movement impairment } \\
\text { (wheelchair user) }\end{array}$ & $\begin{array}{l}\text { Residential care } \\
\text { home }\end{array}$ & Cantonese & English & $\begin{array}{l}\text { Residential } \\
\text { care home }\end{array}$ & Hong Kong \\
\hline Hannah & $34 / F$ & Movement impairment & Day centre & Cantonese & English & With daughter & Hong Kong \\
\hline Angela & $51 / \mathrm{F}$ & Movement impairment & Domiciliary care & English & - & Lived alone & Malaysia \\
\hline Ka-Lai & $64 / F$ & Movement impairment & Day centre & Cantonese & English & Lived alone & Malaysia \\
\hline Mei Ling & $68 / F$ & Movement impairment & Domiciliary care & Cantonese & English & With husband & Malaysia \\
\hline Margaret & $45 / F$ & $\begin{array}{l}\text { Visual impairment and } \\
\text { movement impairment }\end{array}$ & Domiciliary care & English & - & Lived alone & Malaysia \\
\hline Alan & $68 / \mathrm{M}$ & Movement impairment & $\begin{array}{l}\text { Residential care } \\
\text { home }\end{array}$ & English & - & $\begin{array}{l}\text { Residential } \\
\text { care home }\end{array}$ & Malaysia \\
\hline Mr Ko & $65 / M$ & Visual impairment & Day centre & English & - & Lived alone & Malaysia \\
\hline Ah Fong & $53 / F$ & Movement impairment & Domiciliary care & Cantonese & Hakka & Lived alone & Mainland China \\
\hline Mr Yang & $40 / \mathrm{M}$ & $\begin{array}{l}\text { Movement impairment } \\
\text { (wheelchair user) }\end{array}$ & $\begin{array}{l}\text { Residential care } \\
\text { home }\end{array}$ & Mandarin & - & $\begin{array}{l}\text { Residential } \\
\text { care home }\end{array}$ & Mainland China \\
\hline David & $50 / \mathrm{M}$ & Visual impairment & Domiciliary care & Mandarin & - & Lived alone & Mainland China \\
\hline Peter & 19/M & Movement impairment & $\begin{array}{l}\text { Waiting to be } \\
\text { assessed }\end{array}$ & English & - & With mother & Mainland China \\
\hline Mark & $28 / \mathrm{M}$ & $\begin{array}{l}\text { Visual impairment and } \\
\text { movement impairment }\end{array}$ & Domiciliary care & English & - & Lived alone & UK \\
\hline Cecilia & $35 / F$ & Movement impairment & Day centre & English & - & $\begin{array}{l}\text { With husband } \\
\text { and children }\end{array}$ & UK \\
\hline Ann & $50 / F$ & Movement impairment & Domiciliary care & Cantonese & English & With husband & Singapore \\
\hline Betty & $53 / \mathrm{F}$ & Movement impairment & Home care & English & - & With husband & South Africa \\
\hline
\end{tabular}

ment process because they were not able to communicate effectively with the English-speaking social workers. It has been discussed earlier that the inability to taking part in the assessment process can make people feel that their opinions are not valued (Healthcare Commission 2008), which can clearly affect their levels of satisfaction with social care. Participants' stories suggest that although social workers are aware of the importance and procedure to involve interpreters, family is often drawn in to perform the interpreter's role:

At the beginning, the social worker asked an interpreter for help. Now, if they need to speak to me, they will telephone my daughter and ask her to interpret. (Mr Tse)

When the social worker cannot find an interpreter, she will ask my daughter to help. But you know my daughter lives in another city. It causes her troubles to travel here. (CSFG1)
Participants also expressed their concerns that they had exhausted their personal networks when social workers opted to involve their family and friends to play the role of interpreters:

Previously when I met the social worker, a friend came and helped to translate... she helped me many times, not just a couple of times, but now she stops coming. (Mrs Lee)

Apart from the difficulty in getting support from independent interpreters, there are also concerns about the quality of translation. For about 6 months, Mr Yang did not understand the role of the social worker while he was in hospital because:

I didn't know she was a social worker, I didn't know what social worker did. My boss's wife interpreted for me ... but at the beginning; I didn't understand anything they said. Actually the social worker found the boss's wife didn't translate everything for me. 
Poor quality of translation means that social workers are unable to gather accurate information during assessment and hence are not able to provide services to fully meet service users' needs. This in turn can have a determinant effect on levels of satisfaction with the services people receive.

\section{Attitudes of social care workers}

Despite initial difficulties in accessing services, once assessment was completed and services were put in place, a few participants expressed that they appreciated and were happy with the services they received and were impressed by the speedy response from social care. They noted:

There is nothing to improve. I am really happy with the services. I am really satisfied with it. You know we should not keep pushing for more. (Mr Ko)

The social worker gave us a lot of information. She explained to us about options and arranged someone to look after me so that my husband can go out to do shopping and take a break. We are really pleased with the services. (Mrs Lin)

The next stage went quite quickly, a social worker said someone would visit me in a week's time ... and they came. It's just the first stage that you needed to get through was really hard. (Mrs Lam)

A carer, who was present at the interview, expressed her gratitude for the support provided by social care:

At the beginning, there was no one to help, it was very stressful. Now there are people helping me, I feel better, more relaxed ... I am very satisfied with the service. I feel so much better now. (Mr Tse's wife)

Our findings show that the services that are responsive, offer choices and provide a breathing space for their family can improve satisfaction levels. However, most participants did not have positive experiences with social care. Some of them expressed discontent with the uncaring attitudes of the social care workers. They said:

It is just like, they (domiciliary workers) do the job and they can't really be bothered more. (Mei Ling's Husband)

I just feel the social worker is treating me like you're just another hopeless case ... And there is a different care worker every time so I never get any sense of continuity. They don't seem very caring. They just come to do the job, and it isn't a very human experience. (Ah Fong)

Three participants were living in care homes at the time of their interviews and they all complained about the services they received. Mrs Ho found the carers in the care home very frightening. As she was a wheelchair user and relied on care workers to provide personal care, she felt very vulnerable to harm and abuse. She and her family were hesitant to assert their dissatisfaction because of worry of possible reprisal. Her family therefore decided to look for alterative accommodation for her. Worse still, many participants felt that when they were not satisfied with the quality of services, they had no rights to ask for better services and their complaints would not be listened to:

My mother does not like making a fuss. She won't complain, won't say a word even though she is not happy with the home care ... she thinks there is no point to complain. (Mrs Wong's Son)

I have no rights to choose, what can I expect from them even when I am not happy? (David)

Even if I want someone else to help, they won't understand. There's nothing we can do. (Mr Tse)

Mrs Wong's daughter said that her family would rather dig into their pocket to pay for someone to look after her mother than complaining about the care worker's poor attitudes. Many participants tended to adopt a pessimistic view that making their voices heard would yield little change. Some would consider terminating the services or chose to solely rely on personal resources to look after their needs.

Participants who spoke fluent English were more aware of their entitlements to services and were better informed of the organisation of social care. However, they felt frustrated and disappointed with the unresponsive attitudes of social care and the bureaucratic nature of the referral process:

I sent emails and made phone calls to say that I needed a social worker but they were not bothered to reply to phone calls or emails. (ESFG)

Angela had a stroke and as a result, one side of her body was paralysed. However, it took social care a few months to respond to her request for assessment. She recalled:

The social worker probably thought I could pay for a private helper. She didn't offer any alternatives, no. So I had to pay for a helper. I didn't have any assistance for a few months. (Angela)

Participants in the English-speaking focus group were keen to explore different ways to have their voices heard. They agreed:

We could perhaps do with an advocate! We can have different forums on different things so that we can share the 
information. I've found a good way to get results. You go onto the authority's website and go to adult social care complaints, just click onto that. If you send an email, send a copy of the email to someone and just record everything that you do.

\section{Reliance on personal resources}

Participants' stories reveal that despite the input from social care, their needs were not adequately met. Hence, their families remained active in providing care for them:

There's only my husband, he quitted his job to look after me. He does the cleaning, cooking, shopping, taking me to see the doctor. (Mrs Lee)

My wife is the main carer. She wants to visit her family in Hong Kong but she can't, she cannot leave me alone. There are only two of us. If she goes, I cannot manage. (CSFG 2)

The belief in self-reliance also explains why many Chinese families continue to perform their caring responsibility despite the input from social care. Seeking outside help is negatively perceived in Chinese societies as it openly admits that the family is unable to care for their own (Au \& Au 1994, Chan \& O'Connor 2008). Participants remarked:

It's the habit of Chinese, we like being self-reliant. We seldom ask for help. We are not outspoken, so very often our family helps out as much as they can. However, apart from my daughter, I have no relatives to help me. (Alan)

I think basically I need help for everything but naturally I say no to any outside help. My younger brother will help. I think that's a very natural response but apart from my brother, there is no one else to help me. (David)

As most participants were immigrants, many of them experienced breakdown of support networks and were separated from their former social connections in their home countries (Ryan 2011). It was less likely for them to access their extended family networks but to rely on a few family links (Chan 2004, Mak et al. 2007, Rochelle \& Shardlow 2012). This gave rise to their concerns that it could quickly exhaust their family resources from people who had already made sacrifice to care for them such as 'quitting their job' or travelling a long distance to offer help. Holding back his tears, Mr Lau said he felt like a heavy burden to his wife:

I used to work and we had a comfortable life. Now, I have to rely on my wife. She has to go to work and make sure there is food in the house for me. I try to help, try to clean the floor but I can't even see whether the floor is clean. I am such a burden to her.

\section{Using culturally specific services}

A resonate message from all participants demonstrates that they highly valued services that met their language and cultural needs. They complimented the benefits of having Chinese-specific services:

If there is Chinese staff helping me, that's much better. At least we can understand each other. However, there is nothing I can do; I am pleased with the service they provide. (Mr Tse)

At the moment, there are people from the Chinese Association, they really help me. I am fortunate to have them to help me. Otherwise, it's a headache. (CSFG 2)

Apart from addressing their linguistic needs, many participants reported that they relied on day services provided by Chinese welfare organisations to meet their social and dietary needs:

I like going to the Chinese community centre for recreational activities such as Tai Chi, Mahjong (a game originally from China and is played by four players). (Margaret)

In the care home, they only have western food. They give me a few chips and cold salad. The chips are very dry and I have to drink water to swallow them. I want our hot soup. (Mrs Ho)

Our food is different from theirs (the English). At the end of the day, we are not used to what they eat. We like rice porridge, rice, noodles. (Kai-la)

Food plays an important role in Chinese culture and it serves to meet more than one's physical needs (Mclnerney 1992). The predominance of potato-based meals, bread and cold salad is a mismatch for Chinese people's staple diet. Participants reported that they favoured food that was prepared in Chinese ways. As Gunaratnam (2001) suggests, food has significant symbolic implications in healthcare institutions as it represents one's cultural identity. This is particularly important for participants who live in care homes. Both Mr Yang and Alan commented that living in the care home was like serving a life sentence in prison, as they were always surrounded by English-speaking people that they could not converse with. Having Chinese meals served and the opportunity to mingle with other people who share their cultural identity will bring huge benefits to their psychological well-being. This in turn has a positive impact on service satisfaction levels.

\section{Discussion}

Consistent with existing literature (Smedley et al. 2003, Mullan et al. 2009, Liu et al. 2015), this study 
finds that language difference remains a structural barrier for people from Chinese backgrounds when negotiating access to and navigating through public services. Because information about disability support services is mainly produced in English, most participants find it difficult to reach social care. Inability to communicate in English also means that some cannot be fully involved in the assessment and care plan review process and hence are 'disabled' to share their views about their needs and services they receive. Although many local authorities have developed and implemented policies and procedures to involve interpreters in practice, it is worrying to see that when independent interpreters are not available, social workers will approach family members directly and rely on them to communicate. Other studies find that because of the bureaucratic procedure and cost to locate suitable interpreters, professionals often seek family members to facilitate communication, especially in the events of emergency (Chau et al. 2012, Yeung 2013). This further disempowers individuals and can compromise their rights to confidentiality and impartiality (Koo 2012).

It is also disconcerting to learn that participants believed that they had to be hospitalised in order to get support from social care. Many participants only managed to 'muddle through' the system to receive services and remained very unclear about the role of different professionals and the organisation they represented. Uncertainty of the organisation of social care can have significant implications for their secondary help-seeking. This finding is a contribution to existing literature, which highlights the importance of continual support of quality interpreting services throughout the help-seeking and help-receiving process.

Participants in this study shared their strong belief that it was their duty, 'the habit of Chinese', to look after family members and they should not burden with others their caring responsibilities. Family should do their utmost to fulfil their duty as failure to conform to this expectation will bring shame to the family (Chan \& O'Connor 2008, Koo 2012). However, Chinese people are not immune to the stress brought forth by caring for relatives with physical disabilities. The strong emotional response from participants during the interview process reflects that they are deeply concerned about their close families as they have to bear the caring responsibility for their long-term care need. Here, we can see the dilemma faced by the participants because of the cultural expectation of looking after their own and the limited support from their small close-knit family network. This explains why they only come into contact with social care when their families reach a breaking point. Our find- ings also help us understand why some participants really appreciated the external support provided by social care as it helped to alleviate the stress of their overstrained small support networks, especially for those families who were already exhausted before they reached social care.

This study finds that most participants were disinclined to complain even though they were displeased with the quality of services. Previous research evidence suggests that it is uncharacteristic of Chinese character to speak out about personal suffering and assert their needs in the public domain (Chan \& O'Connor 2008). In traditional Chinese society, much emphasis is placed on social harmony, and individual rights should give way to collective goods. Hence, Chinese people are reluctant to complain and will avoid open confrontation if possible (Hwang 2012). However, findings here suggest that this cultural factor does not fully explain participants' reticence to complain. Participants expressed that they could not expect a lot from social care and felt that they had no rights to voice their opinions. They also adopted a pessimistic view that 'there is nothing they can do' and their complaints would fall on deaf ears as social care would not be able to understand their needs. Feeling unable to voice their opinions about the services they receive can have negative effects on satisfaction levels as social care is unable to learn from their experiences and make appropriate adjustment to meet their needs. This explains why some will terminate services or remain reliant on their family to care for them. We argue here that to enable them to fully utilise social care services, resources to inform their citizen rights and to support them to articulate their concerns should be made available.

Additionally, our findings show that participants who were proficient in English found it easier to navigate through the system to seek help. Perhaps, it is because they can access disability literature and hence are more aware of the routes and their rights to services (Nguyen \& Lee 2012). However, they are not impressed by the unresponsive bureaucracy. Proficiency in English means that they are better informed of different channels to articulate their dissatisfaction and challenge malpractice. They are also more proactive in exploring different avenues to voice their concerns. This challenges the stereotypical views about people from Chinese backgrounds that they are reluctant to assert their views. It also lends support to our earlier claim that structural factors in part hinder Chinese people from expressing their concerns about the services they receive from social care.

This study finds that those who stay in care homes are more isolated, most unhappy and vulnera- 
ble as they are unable to communicate with care workers, and their food preferences and social needs are not adequately catered for. A strong theme emerging from the data indicates that participants felt more at ease and more comforted if care workers could communicate with them in their native language. This highlights the important role played by Chinese welfare organisations (Fisher \& Glanfield 2009, Mullan et al. 2009). The use of Chinese care workers means that it can help to resolve communication barriers and better meet the cultural needs of people from Chinese backgrounds as their food can be prepared in a way that they appreciate (Payne et al. 2008, Mullan et al. 2009).

The findings from our study suggest that participants generally had no or low expectations of social care and indeed some did not expect to receive any services at all. This is particularly evident among the migrant community who have no previous experience of disability support services in their home country (Fisher \& Glanfield 2009, Liu et al. 2015). Payne et al.'s (2008) study found that first-generation migrants feel that because of their second-class citizen status, they should not keep pushing for more from the government. Others perceive that the western model of delivery and organisation of health and social care services are not compatible with the way they conceptualise their needs and hence do not see the point of using mainstream services (Liu et al. 2014). For some, this explains their high levels of satisfaction if a service is offered, but for others it could result in disengagement from services.

\section{Limitations of the study}

The findings of the study should be treated with caution, given the sample size was relatively small. Also, nearly all participants are of immigrant backgrounds and reside in cities where support services provided by Chinese welfare organisations are available. Therefore, the experiences of those who were born in the $\mathrm{UK}$, and live in rural areas and have limited access to Chinese welfare organisations are under-represented in this study. It is also interesting to note that no participants reported that they experienced stigma concerning their physical competence and bodily appearance. Further enquiry into this area is required to explore how it may impede help-seeking.

\section{Conclusion}

Our study finds that experiences of social care among people from Chinese backgrounds are influenced by structural and cultural factors. It is an ongoing struggle especially for those who are not proficient in English, to negotiate access and organisation of their social care. The findings clearly show that many participants remain confused about the organisation of social care and they can be easily lost in the system. Social care service needs to be aware of the tension between their reluctance to receive support outside family and the demand of caring responsibility placed on the family. Hence, the role of the family should not be overrated. It is evident that the participants and their families initially welcome the input from social care as it provides a breathing space for the family. However, when families find that social care cannot adequately meet their needs, they feel that they cannot and should not voice their dissatisfaction. Instead, they will consider resuming their 'duty' and remain active in caring for their relative. To fully meet the social care needs of people with physical disabilities from Chinese backgrounds and improve service satisfaction levels, social care needs to address these structural and cultural factors. A clear communication strategy that takes account of the verbal and written languages used by the diverse set of Chinese communities in England is needed. Chinese welfare organisations are best placed to support and empower this marginalised community to help them understand and assert their rights. They play a crucial role to meet the linguistic and cultural needs of Chinese people. If social care is committed to promote early access, equality and fair treatment, continuous commitment and closer collaboration with Chinese welfare organisations are needed.

\section{Acknowledgments and Disclaimer}

This study was funded by the National Institute of Health Research for Social Care Research in England. The views expressed in this article are those of the authors and not necessarily those of the funding body. We thank the participants for taking part in the study.

\section{References}

Aspinall P. (2007) Language ability: a neglected dimension in the profiling of populations and health service users. Health Education Journal 66 (1), 90-106.

$\mathrm{Au}$ W.K.L. \& Au K.P.K. (1994) Care in the Chinese Community - The Way Forward. Merseyside Chinese Community Development Association, Liverpool.

Bignall T. \& Butt J. (2000) Between Ambition and Achievement: Young Black Disabled People: Views and Experiences of Independence and Independent Living. Polity Press and JRF, Bristol and York. 
Bradbury-Jones C., Sambrook S. \& Irvine F. (2009) The phenomenological focus group: an oxymoron? Journal of Advanced Nursing 65 (3), 663-671.

Care Quality Commission (2010) Count Me in 2009: Results of the 2009 National Census of Inpatients and Patients on Supervised Community Treatment in Mental Health and Learning Disability Services in England and Wales. Care Quality Commission and National Mental Health Development Unit, Newcastle upon Tyre.

Chahal K. (2004) Experiencing Ethnicity: Discrimination and Service Provision. Joseph Rowntree Foundation, York.

Chan M.C.K. (1987) The needs of Chinese community in Britain. In: S. Roper (Ed.) The Needs of the Chinese Community in the North West, pp. 7-9. Commission for Racial Equality, London.

Chan C.K. (2004) A Study of Help-Seeking Behaviours among UK Chinese Families. Economic and Social Research Council, Swindon.

Chan S.M. \& O'Connor D. (2008) Finding a voice: the experiences of Chinese family members participating in family support groups. Social Work with Groups 31 (2), 117-135.

Chau R.C.M., Yu S.W.K. \& Tran C.T.L. (2012) Understanding the diverse health needs of Chinese people in Britain and developing cultural sensitive services. Journal of Social Work 12 (4), 385-403.

Chow J., Auh E., Scharlach A., Lehning A. \& Goldstein C. (2010) Types and sources of support received by family caregivers of older adults from diverse racial and ethnic groups. Journal of Ethnic and Cultural Diversity in Social Work 19 (3), 175-194.

Department of Health (2012) Equality Objectives Action Plan: September 2012-December 2013. Available at: https://www. gov.uk/government/uploads/system/uploads/attachment data/file/216801/DH-Equality-Objectives-Action-Plan.pdf (Accessed 17/12/2014)

Dobbs J., Green H. \& Zealey L. (2006) Focus on Ethnicity and Religion. National Statistics Office, Palgrave Macmillan, Hampshire.

Fisher K. \& Glanfield G. (2009) Services for people with disability from Chinese backgrounds. Social Policy Research Centre Newsletter 101 (1), 4-5.

Gunaratnam Y. (2001) Eating into multiculturalism: hospice staff and service users talk food, 'race', ethnicity, culture and identity. Cultural Social Policy 21 (3), 287-310.

Health and Social Care Information Centre (2013) Community Care Statistics, Social Services Activity, England 20122013, Final Release. The Health and Social Care Information Centre, Leeds.

Healthcare Commission (2008) Report on Self-Reported Experience of Patients from Black and Minority Ethnic Groups. Department of Health, London.

Hiew Y., Lok S., Hollingsbee C., Man W. \& Yan C. (2008) Report of the Community Led Research Project Focussing on 'Investigating the Barriers and Difficulties Faced by the Older Chinese People in Tower Hamlets and Hackney in Coping with Mental Health Issues'. The National Institute for Mental Health in England, London.

Holroyd E. (2003) Chinese cultural influences on parental caregiving obligations toward children with disabilities. Qualitative Health Research 13 (1), 4-19.

Huang S.L. \& Spurgeon A. (2006) The mental health of Chinese immigrants in Birmingham, UK. Ethnicity and Health 11 (4), 365-387.
Hwang K.K. (2012) Foundation of Chinese Psychology: Confucian Social Relations. Springer, New York.

Katbamna S., Ahmad W., Bhakta P., Baker R. \& Parker G. (2004) Do they look after their own? Informal support for South Asian carers. Health and Social Care in the Community 12 (5), 398-406.

Kim H.S., Sherman D.K., Ko D. \& Taylor S.E. (2006) Pursuit of comfort and pursuit of harmony: culture, relationships, and social support seeking. Personality and Social Psychology Bulletin 32 (12), 1595-1607.

Koo K. (2012) Carers' representations of affective mental disorders in British Chinese communities. Sociology of Health and Illness 34 (8), 1140-1155.

Liu Z., Speed S. \& Beaver K. (2012) Perceptions and attitudes towards exercise among Chinese elders the implications of culturally based self-management strategies for effective health-related help seeking and person-centred care. Health Expectations 18 (2), 262-272.

Liu Z., Beaver K. \& Speed S. (2014) Being healthy: a grounded theory study of help seeking behaviour among Chinese elders living in the UK. International Journal of Qualitative Study on Health and Well-being 9, $1-9$.

Liu Z., Beaver K. \& Speed S. (2015) Chinese Elders' views on their interactions in general practice: a Grounded Theory study. Ethnicity and Health 20 (2), 129-144.

Mak A.K., Mackenzie A. \& Lui M. (2007) Changing needs of Chinese family caregivers of stroke survivors. Journal of Clinical Nursing 16 (5), 971-979.

Manthorpe J., Moriarty J., Rapaport J. et al. (2008) There are wonderful social workers but it's a lottery': older people's views about social workers. British Journal of Social Work 38 (6), 1132-1150.

Mclnerney F. (1992) Provision of food and fluids in terminal care: a sociological analysis. Social Science and Medicine $\mathbf{3 4}$ (11), 1271-1276.

Moustakas C. (1994) Phenomenological Research Methods. Sage Publication, Thousand Oaks, CA.

Mullan J.T., Grossman B.R., Hernandez M., Wong A., Eversley R. \& Harrington C. (2009) Focus group study of ethnically diverse low-income users of paid personal assistance services. Home Health Care Service Quarterly 28 (1), 24-44.

Ng A., Hiew Y., Lok S. \& Tang R. (2007) Report of the Community Led Research Project Focussing on the Exploration of the Mental Health Needs and Experiences of the Chinese Community in Barnet. Chinese Mental Health Association, London.

Nguyen D. \& Lee R. (2012) Asian immigrants' mental health service use: an application of the life course perspective. Asian American Journal of Psychology 3 (1), 53-63.

Office for National Statistics (2012) Ethnicity and National Identity in England Wales 2011. Office for National Statistics, London.

Partridge M. (2013) Including People with Learning Difficulties from Chinese Backgrounds: An Ethnography of Three Services. University of Bristol, Bristol.

Payne S., Seymour J., Chapman A. \& Holloway M. (2008) Older Chinese people's views on food: implications for supportive cancer care. Ethnicity and Health 13 (5), 497-514. 
Rochelle T.L. \& Marks D.F. (2010) Medical pluralism of the Chinese in London: an exploratory study. British Journal of Health Psychology 15 (4), 715-728.

Rochelle T.L. \& Shardlow S.M. (2012) Quality of social networks among UK Chinese. Social Indicators Research 114 (2), 425-439.

Ryan L. (2011) Migrants' social networks and weak ties: accessing resources and constructing relationships postmigration. The Sociological Review 59 (4), 707-724.

Ryder A.G., Bean G. \& Dion K.L. (2000) Caregiver responses to symptoms of first-onset psychosis: a comparison study of Chinese and Euro-Canadian families. Transcultural Psychiatry 37 (2), 225-235.

Smedley B.D., Stith A.Y. \& Nelson A.R. (2003) Unequal Treatment: Confronting Racial and Ethnic Disparities in Health Care. National Academies Press, Washington, DC.

Van Manen M. (1997) Researching lived experience: human science for an action sensitive pedagogy. Althouse Press, London, Ontario.

Waller J., Robb K., Stubbings S., Ramirez A., Macleod U., Austoker J. et al. (2009) Awareness of cancer symptoms and anticipated help seeking among ethnic minority groups in England. British Journal of Cancer 101, S24-S30.

Westbrook M., Legge V. \& Pennay M. (1993) Attitudes towards disabilities in a multicultural society. Social Science and Medicine 36 (5), 615-623.

Wong M. (2006) Chinese in Burton and Southeast Staffordshire: A Baseline Community Needs Assessment. Chinese National Healthy Living Centre, London.

Yeung E.Y.W. (2013) Role of Social Networks in the Pathway to Care of Chinese People Living with a Diagnosis of Severe Mental Illness in England. Unpublished PhD. The University of Hong Kong, Hong Kong.

Yeung E.Y.W., Irvine F., Ng S.M. \& Tsang K.M. (2013) Role of social networks in the help-seeking experiences among Chinese suffering from severe mental illness in England: a qualitative study. British Journal of Social Work 43 (3), 486-503.

Yu S.W.K. (2000) Chinese Older People: A Need for Social Inclusion in Two Communities. Joseph Rowntree Foundation and Policy Press, Bristol. 